University of Nebraska - Lincoln

DigitalCommons@University of Nebraska - Lincoln

\title{
Silver Nanocluster-Embedded Zein Films as Antimicrobial Coating Materials for Food Packaging
}

\author{
Lei Mei \\ University of Maryland \\ Zi Teng \\ University of Maryland \\ Guizhi Zhu \\ National Institutes of Health \\ Yijing Liu \\ National Institutes of Health \\ Fuwu Zhang \\ National Institutes of Health \\ See next page for additional authors
}

Follow this and additional works at: https://digitalcommons.unl.edu/usdaarsfacpub

Mei, Lei; Teng, Zi; Zhu, Guizhi; Liu, Yijing; Zhang, Fuwu; Zhang, Jinglin; Li, Ying; Guan, Yongguang; Luo, Yaguang; Chen, Xianggui; and Wang, Qin, "Silver Nanocluster-Embedded Zein Films as Antimicrobial Coating Materials for Food Packaging" (2017). Publications from USDA-ARS / UNL Faculty. 1798. https://digitalcommons.unl.edu/usdaarsfacpub/1798

This Article is brought to you for free and open access by the U.S. Department of Agriculture: Agricultural Research Service, Lincoln, Nebraska at DigitalCommons@University of Nebraska - Lincoln. It has been accepted for inclusion in Publications from USDA-ARS / UNL Faculty by an authorized administrator of DigitalCommons@University of Nebraska - Lincoln. 


\section{Authors}

Lei Mei, Zi Teng, Guizhi Zhu, Yijing Liu, Fuwu Zhang, Jinglin Zhang, Ying Li, Yongguang Guan, Yaguang Luo, Xianggui Chen, and Qin Wang 


\title{
Silver Nanocluster-Embedded Zein Films as Antimicrobial Coating Materials for Food Packaging
}

\author{
Lei Mei, ${ }^{\dagger}$ Zi Teng, ${ }^{\dagger}$ Guizhi Zhu, ${ }^{\dagger}$ Yijing Liu, ${ }^{\ddagger}$ Fuwu Zhang, ${ }^{\ddagger}$ Jinglin Zhang, ${ }^{\dagger} \odot$ Ying Li, ${ }^{\dagger \odot}$
}

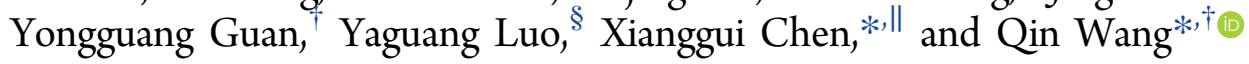

${ }^{\dagger}$ Department of Nutrition and Food Science, College of Agriculture and Natural Resources, University of Maryland, College Park, Maryland 20740, United States

${ }^{\ddagger}$ Laboratory of Molecular Imaging and Nanomedicine, National Institute of Biomedical Imaging and Bioengineering (NIBIB), National Institutes of Health (NIH), Bethesda, Maryland 20892, United States

${ }^{\S}$ Environmental Microbial and Food Safety Laboratory, USDA-ARS, 10300 Baltimore Avenue, Building 002, Beltsville, Maryland 20705, United States

"School of Food and Bioengineering, Xihua University, Chengdu, Sichuan 610039, China

Supporting Information

ABSTRACT: Highly efficient antimicrobial agents with low toxicity and resistance have been enthusiastically pursued to address public concerns on microbial contamination in food. Silver nanoclusters (AgNCs) are known for their ultrasmall sizes and unique optical and chemical properties. Despite extensive studies of AgNCs for biomedical applications, previous research on their application as antimicrobials for food applications is very limited. Here, for the first time, by incorporating $\operatorname{AgNCs}(\sim 2 \mathrm{~nm}$ in diameter) into zein films that are widely used as food packaging materials, we developed a novel coating material with potent antimicrobial activity, low toxicity to human cells, and low potential to harm the environment. In addition, we systematically evaluated the

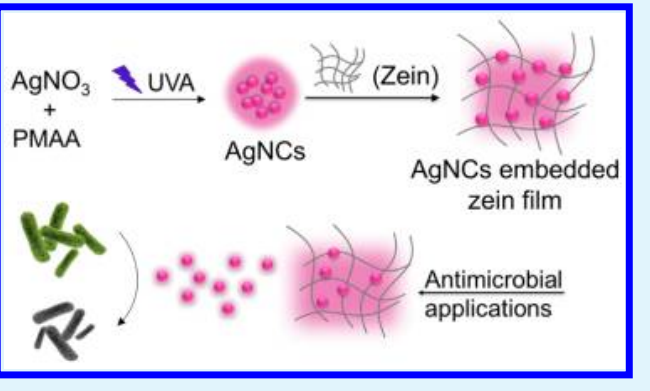
antimicrobial activities and cytotoxicity of AgNCs-embedded zein films and compared them to zein films embedded with $\mathrm{AgNO}_{3}$ or $\mathrm{Ag}$ nanoparticles with diameters of 10 and $60 \mathrm{~nm}$ (AgNP10 and AgNP60, respectively). At equivalent silver concentrations, $\mathrm{AgNCs}$ and $\mathrm{AgNO}_{3}$ solutions exhibited considerably higher antimicrobial activities than those of AgNP10 and AgNP60 solutions. Moreover, AgNCs exhibited less cytotoxicity to human cells than $\mathrm{AgNO}_{3}$, with a half maximal inhibitory concentration $\left(\mathrm{IC}_{50}\right)$ of $34.68 \mu \mathrm{g} / \mathrm{mL}$ for AgNCs, compared to $9.14 \mu \mathrm{g} / \mathrm{mL}$ for $\mathrm{AgNO}_{3}$. Overall, the novel AgNCs coating developed in this research has great potential for antimicrobial applications in food packaging materials due to its high antimicrobial efficacy, ultrasmall size, and low cytotoxicity.

KEYWORDS: Silver nanoclusters, zein, antimicrobial agent, coating material, food packaging

\section{INTRODUCTION}

Microbial contamination reduces the shelf life of food products, increases the risk of foodborne illness, and causes huge economic losses to the food industry. One approach to combating microbial contamination in the food supply is to develop antimicrobial food packaging systems and coating materials, which incorporate antimicrobial agents that can interact with food or headspace in the package to extend the shelf life of food products and enhance food safety without affecting food quality. ${ }^{1}$

Silver and silver-based compounds have been used as broadspectrum antimicrobial agents for centuries. They are known to have antimicrobial activity against many different strains of bacteria, fungi, and viruses and are stable due to their low volatility. They have been incorporated into food containers, ${ }^{2}$ paints, ${ }^{3}$ medical devices, ${ }^{4}$ and wound dressings ${ }^{5}$ to prevent microbial contamination and bacterial infection. Among them, silver nanoparticles (AgNPs) have attracted much attention for their unique physical properties, including strong surface plasma resonance, large surface to volume ratio, efficient catalytic activity, and remarkable antimicrobial activity. ${ }^{6}$ The antimicrobial activities of AgNPs are reported to be highly dependent on the particle size. ${ }^{7}$ Decreased particle size contributes to higher antimicrobial activity as a result of increased mobility and surface area to volume ratio, resulting in greater interaction with bacteria. For example, MartinezCastanon et al. demonstrated that, by reducing the sizes of AgNPs from 89 to $7 \mathrm{~nm}$, the minimum inhibitory concentration (MIC) dropped from 11.79 to $6.26 \mu \mathrm{g} / \mathrm{mL}$ for E. coli and from 33.17 to $7.5 \mu \mathrm{g} / \mathrm{mL}$ for S. aureus. ${ }^{8}$ Small AgNPs could attach to and penetrate the cell membrane, altering the permeability and cellular respiration, and causing further damage to intracellular biomolecules such as genomic DNA. ${ }^{9}$ Although the development of silver-based antimicrobial pack-

Received: June 7, 2017

Accepted: September 19, 2017

Published: September 19, 2017 
aging materials has advanced greatly in the past decades, many challenges remain to be addressed: (1) creating sustainedrelease delivery systems of antimicrobials to ensure prolonged antimicrobial efficacy; ${ }^{10,11}$ (2) minimizing antimicrobial agents' toxicity to human; (3) reducing the residual antimicrobial agents or antimicrobial packaging materials in order to reduce environmental hazard. ${ }^{12-14}$ In this study, we have addressed these challenges by incorporating AgNCs as antimicrobial agents for their broad antimicrobial spectrum, ultrasmall particle size, low cytotoxicity, and highly efficient antimicrobial effects.

AgNCs, consisting of dozens of atoms, have a diameter about $2 \mathrm{~nm}$, which is close to the Fermi wavelength $(\sim 0.5 \mathrm{~nm}$ for $\mathrm{Ag}$ ). With such small sizes, the band structures of AgNCs are discontinuous and break down into discrete energy levels, and AgNCs thus endow unique physical and chemical properties (such as tunable fluorescence with great photostability and quantized charging property), which are different from AgNPs with larger particle sizes. ${ }^{15,16}$ Conventionally, AgNCs are synthesized by reducing $\mathrm{Ag}^{+}$using chemical reductants or light irradiation. Since AgNCs tend to interact with each other and aggregate to reduce their surface energy, stabilizers or templates (e.g., DNA, polymers et al.) are critical for the stability of AgNCs. ${ }^{17}$ AgNCs enabled various applications. For example, Wang et al. reported the use of core-shell structured nanoparticles with hydrophilic surfaces and hydrophobic cores as templates to synthesize AgNCs, in which the templates greatly enhanced the stability and fluorescence intensity of AgNCs. ${ }^{18}$ Previously, AgNCs have been extensively investigated for applications of biosensing, ${ }^{19}$ bioimaging, ${ }^{20}$ and disease diagnosis; ${ }^{21}$ however, the exploration of the antimicrobial application of AgNCs, though highly promising, has been limited, especially for food packaging applications. Compared to AgNPs larger than $10 \mathrm{~nm}$, the ultrasmall size of AgNCs impart unique advantages such as a large surface to volume ratio, high local surface $\mathrm{Ag}$ concentration, and high mobility. These advantages enhance the antimicrobial potency of AgNCs, enabling the achievement of superior antimicrobial capacity using much smaller amounts of AgNCs than is possible with AgNPs. ${ }^{22-24}$ However, the antimicrobial activity of AgNCs remains to be systematically studied and compared with $\mathrm{AgNPs}$ and $\mathrm{AgNO}_{3}$ solution.

Zein, a group of prolamins from corn, is a Generally Recognized As Safe (GRAS) food-grade ingredient. ${ }^{25}$ Zein films have low water vapor permeability compared to many other biobased films, because three-quarters of the amino acid residues in zein are hydrophobic. ${ }^{26}$ Zein films have previously been developed as antimicrobial food packaging materials by incorporating antimicrobial lysozyme and thymol. ${ }^{27}$ Compared with these biological based antimicrobials, zein films embedded with inorganic and highly potent AgNCs may offer unique advantages such as high efficacy and low volatility.

In this work, we aim to develop a novel antimicrobial coating material for food packaging. We optimized the synthesis of ultrasmall AgNCs in water using polymethacrylic acid (PMAA) as a stabilizer and characterized the AgNC-embedded zein films. Further, we systematically evaluated the antimicrobial activities and cytotoxicity of the resulting AgNC-embedded zein films by comparing them with zein films that were incorporated with $\mathrm{AgNO}_{3}$ and AgNPs. The developed films showed potent antimicrobial activity and low toxicity to human cells. We envision that, by a simple dry-cast process, this material can be coated and combined with other packaging materials to further enhance antimicrobial potency and broaden the spectra of antimicrobial activity.

\section{MATERIALS AND METHODS}

2.1. Materials. Silver nitrate was purchased from VWR International (Radnor, Pennsylvinia, USA). PMAA was obtained from Polysciences, Inc. (Warrington, Florida, USA). Silver nanoparticles of 10 and $60 \mathrm{~nm}$ in diameter were purchased from Alfa Aesar (Haverhill, Massachusetts, USA). Zein was purchased from MP Biomedicals (Santa Ana, California, USA), and ethyl alcohol (ACS grade) was purchased from Pharmco-Aaper (Shelbyville, Kentuchy, USA).

2.2. Synthesis of Fluorescent AgNCs. AgNCs were synthesized using modifications to a previously reported method. ${ }^{24}$ Briefly, a mixture of $\mathrm{AgNO}_{3}$ and PMAA in deionized water was reduced by ultraviolet-A irradiation at wavelengths ranging from 315 to $400 \mathrm{~nm}$ (UVA Lamp, Sankyo Denki, Japan). To optimize the synthesis conditions to achieve maximum florescence emission in minimum time, $\mathrm{AgNO}_{3}$ and PMAA were dissolved in deionized water with concentration ratios varying from 2:1 to $20: 1$, followed by exposure to UVA for a series of times. The fluorescence emission of the reducing product was measured every $15 \mathrm{~min}$ with excitation at $512 \mathrm{~nm}$ for a maximum of 7.5-h UVA exposure.

Synthesis of AgNCs for the silver release profile, toxicity, and antimicrobial studies proceeded by reducing $60 \mathrm{mg} / \mathrm{mL} \mathrm{AgNO}_{3}$ and $10 \mathrm{mg} / \mathrm{mL}$ PMAA with $60 \mathrm{~min}$ UVA exposure, according to the optimal conditions determined in preliminary experiments. After 60 min exposure to UVA light, the solution acquired a pink color, which indicated the formation of AgNCs. The synthesized AgNCs solution was then filtered with dialysis bags (MWCO $1 \mathrm{KDa}$, Spectrum Laboratories, INC, US) to remove unreacted silver ions and stored in a refrigerator for future use. The yield of AgNCs was $10 \%$, which was estimated from Inductively Coupled Plasma (ICP) measurements (ICPE-9000, Shimadzu, Kanagawa, Japan). Briefly, a $1 \mathrm{~mL}$ stock solution of $\mathrm{AgNCs}$ was diluted 10 times with $5 \%(\mathrm{v} / \mathrm{v})$ aqueous nitrous acid, and $\mathrm{AgNO}_{3}$ was dissolved by $5 \%(\mathrm{v} / \mathrm{v})$ aqueous nitrous acid at concentrations of $0.01,0.1,1,10$, and $100 \mathrm{mg} / \mathrm{mL}$ with a final volume of $10 \mathrm{~mL} . \mathrm{AgNO}_{3}$ solution samples were first tested by ICP to generate the standard curve, and then AgNCs samples were tested.

Synthesis of AgNC-embedded zein film was achieved by dissolving $100 \mathrm{mg}$ zein protein in $1 \mathrm{~mL}$ of $70 \%(\mathrm{v} / \mathrm{v})$ aqueous ethanol and adding AgNC solution to the ethanol in a 3:7 (v/v) ratio. The zein solution and AgNCs in ethanol were later mixed with a ratio of 1:1 (v/ $v)$. The mixture was used to coat disk paper or agar for further experiments through a dry-cast process.

2.3. Characterization of AgNCs. After synthesis, AgNCs were characterized for their fluorescence, morphology, and surface charges. The fluorescence of $\mathrm{AgNCs}$ was measured using a microplate reader (SpectraMax, Molecular Devices, LLC, California, USA) with the emission range $560-700 \mathrm{~nm}$ with excitation at $510 \mathrm{~nm}$. The morphology of AgNCs was observed via scanning transmission electron microscopy (STEM). Samples were prepared for microscopy as follows. The purified stock solution of AgNCs was diluted 50 times with deionized water, and $5 \mu \mathrm{L}$ of the diluted solution werew dried on a microscopy grid (400 mesh ultrathin carbon film on lacey carbon support film, Ted Pella, INC, US) under the hood for $1 \mathrm{~h}$. The sample $\mathrm{AgNC}$ and zein mixture was prepared for STEM by mixing $0.5 \mu \mathrm{L}$ of AgNCs stock solution with $4.5 \mu \mathrm{L}$ of $0.01 \%$ zein in $70 \%$ ethanol, and then dropping $5 \mu \mathrm{L}$ of the mixture on a carbon grid and drying under the hood for $1 \mathrm{~h}$. These grids were later imaged using STEM (JEM 2100 FEG TEM/STEM, JEOL, Tokyo, Japan), and the size distribution was measured and analyzed using the software ImageJ (National Institutes of Health, USA). The zeta potential was measured on a Zetasizer Nano (Malvern Instruments Ltd., Worcestershire, UK), using $1 \mathrm{~mL}$ each of AgNC solution, AgNC and zein mixture, AgNP10 and zein mixture, AgNP60 and zein mixture, and zein mixture in 70\% ethanol aqueous solution.

2.4. Assessment of Antimicrobial Activity. The agar diffusion test and growth curve measurement were applied to a pathogenic 
strain of E. coli $\mathrm{O} 157: \mathrm{H} 7$ to examine the antimicrobial efficacy of different silver composites. For the agar diffusion assay, AgNCs, $\mathrm{AgNO}_{3}, \mathrm{AgNP} 10$, and AgNP60 were dissolved in deionized water (DI water) with concentrations of 2 and $0.4 \mathrm{mg} / \mathrm{mL} \mathrm{Ag}$ equivalents, respectively. Then, $5 \mu \mathrm{L}$ of each sample were spread and allowed to dry on diffusion disks (VWR International, Radnor, Pennsylvinia, USA) with diameters of $7 \mathrm{~mm}$; thus, each disk contained $10 \mu \mathrm{g}$ or $2 \mu \mathrm{g}$ $\mathrm{Ag}$ equivalents. The diffusion disks were further dried under the hood, followed by loading an additional $5 \mu \mathrm{L}$ of $10 \%$ zein solution and drying. One colony of E. coli O157:H7 was dispersed and incubated in tryptic soy broth (TSB, VWR International, Radnor, Pennsylvinia, USA) at $37{ }^{\circ} \mathrm{C}$ for $16 \mathrm{~h}$, and $100 \mu \mathrm{L}$ of bacteria suspension (absorbance at $\mathrm{OD}_{600}: 1$ ) were spread evenly on tryptic soy agar (25 $\mathrm{mL}$ tryptic soy agar per dish, Sigma-Aldrich, St. Louis, Missouri, USA). The dried disks were then placed on the plates. Diffusion disks loaded with $5 \mu \mathrm{L}$ of TSB, $5 \mu \mathrm{L}$ of $10 \%$ zein solution, and $3.4 \mu \mathrm{L}$ of $0.05 \%$ PMAA solution (equivalent to the amount of PMAA in AgNCs with $10 \mu \mathrm{g}$ silver equivalents) were used in the control group. After incubating the plates at $37{ }^{\circ} \mathrm{C}$ for 24 or $72 \mathrm{~h}$, the width of the inhibition rings surrounding the disks were measured with a ruler. ${ }^{28}$ The antimicrobial activity of bare $\mathrm{AgNCs}, \mathrm{AgNO}_{3}, \mathrm{AgNP} 10$, and AgNP60 (without zein coating) was also studied by measuring the growth curves of $E$. coli $\mathrm{O} 157: \mathrm{H} 7$ exposed to the different treatments. E. coli was cultured in TSB for $16 \mathrm{~h}$ and diluted with TSB to an optical density (OD) at $600 \mathrm{~nm}$ of 0.05 . The diluted bacteria were then incubated with $\mathrm{AgNCs}, \mathrm{AgNO}_{3}, \mathrm{AgNP} 10$, and $\mathrm{AgNP} 60$ with final concentrations of 1,5 , or $10 \mu \mathrm{g} / \mathrm{mL}$ Ag equivalents, respectively, for 9 $\mathrm{h}$ in a $37{ }^{\circ} \mathrm{C}$ incubator. The absorbance or OD of each sample at 600 $\mathrm{nm}$ was then measured every $0.5 \mathrm{~h}$ with a $\mathrm{UV} /$ vis spectrophotometer (Beckman Coulter, Brea, CA, USA). ${ }^{21}$ To test the MIC of AgNCs, $\mathrm{AgNO}_{3}, \mathrm{AgNP} 10$, and AgNP60. Mueller-Hinton agars were coated by AgNCs, $\mathrm{AgNO}_{3}, \mathrm{AgNP} 10$, and AgNP60 embedded films with silver concentrations of $0.525,1.05,2.1,4.2,8.4,16.8,33.6,67.2,134.4,168$, 201.6, and $235.2 \mu \mathrm{g} / \mathrm{cm}^{2}$. Agars coated with plain zein film were used as the control. Then, $100 \mu \mathrm{L}$ of bacteria suspension $\left(\mathrm{OD}_{600}=1.0\right)$ were evenly spread on the pretreated agar and incubated at $37^{\circ} \mathrm{C}$ for $24 \mathrm{~h}$. The lowest silver concentrations that resulted in no visible growth of microorganisms were determined as the MIC.

2.5. Cell Viability. The cytotoxicity test of AgNCs, AgNP10, AgNP60, and $\mathrm{AgNO}_{3}$ was performed on human cell line HCT116 (ATCC, Manassas, VA). Briefly, the cells were seeded on 96-well plates and incubated overnight for adhesion, followed by adding 0.2, $0.4,0.8,1.6,3.2,6.4,12.8,25.6,51.2$, or $102.4 \mu \mathrm{g} / \mathrm{mL}$ of AgNCs, AgNP10, AgNP60, or $\mathrm{AgNO}_{3}$ dissolved in Dulbecco's Modified Eagle Medium (Thermo Fisher Scientific, Waltham, Massachusetts, USA), respectively. After incubating for $48 \mathrm{~h}$, the cell viability was measured by the cell counting kit-8 (Dojindo Molecular Technologies, Maryland, USA). Specifically, $10 \mu \mathrm{L}$ of cck- 8 solution were added to each well of cells and incubated for around $2 \mathrm{~h}$. The absorbance at 450 $\mathrm{nm}$ was recorded by a plater reader (SpectraMax, Molecular Devices, Sunnyvale, California, USA), and cell viability was calculated according to the manufacturer's guidance. Results were analyzed in GraphPad Prism 7 (GraphPad Software, Inc., La Jolla, California, USA).

2.6. Statistics. The experimental results were analyzed using GraphPad Prism 7 (GraphPad Software, Inc., La Jolla, California, USA) with significance level $p<0.05$. Two-way ANOVA and Tukey's multiple comparisons test were conducted for the agar diffusion test data. One-way ANOVA and Bonferroni post-test were conducted for the cell viability data.

\section{RESULTS AND DISCUSSION}

3.1. Synthesis, Optimization, and Characterization of AgNCs. AgNCs were synthesized by reducing silver ions via UVA irradiation with PMAA as a stabilizer. The effects of irradiation time, concentration of $\mathrm{AgNO}_{3}$ and PMAA, ratio of $\mathrm{AgNO}_{3}$ to PMAA, and light sources (e.g., UVA lamp, linear light bulb, and sun light) on the formation and fluorescence intensity of AgNCs were systematically investigated. The fluorescence emission results for different UVA irradiation times are shown in Figure 1A. The fluorescence intensity increased rapidly at the beginning of the reduction due to

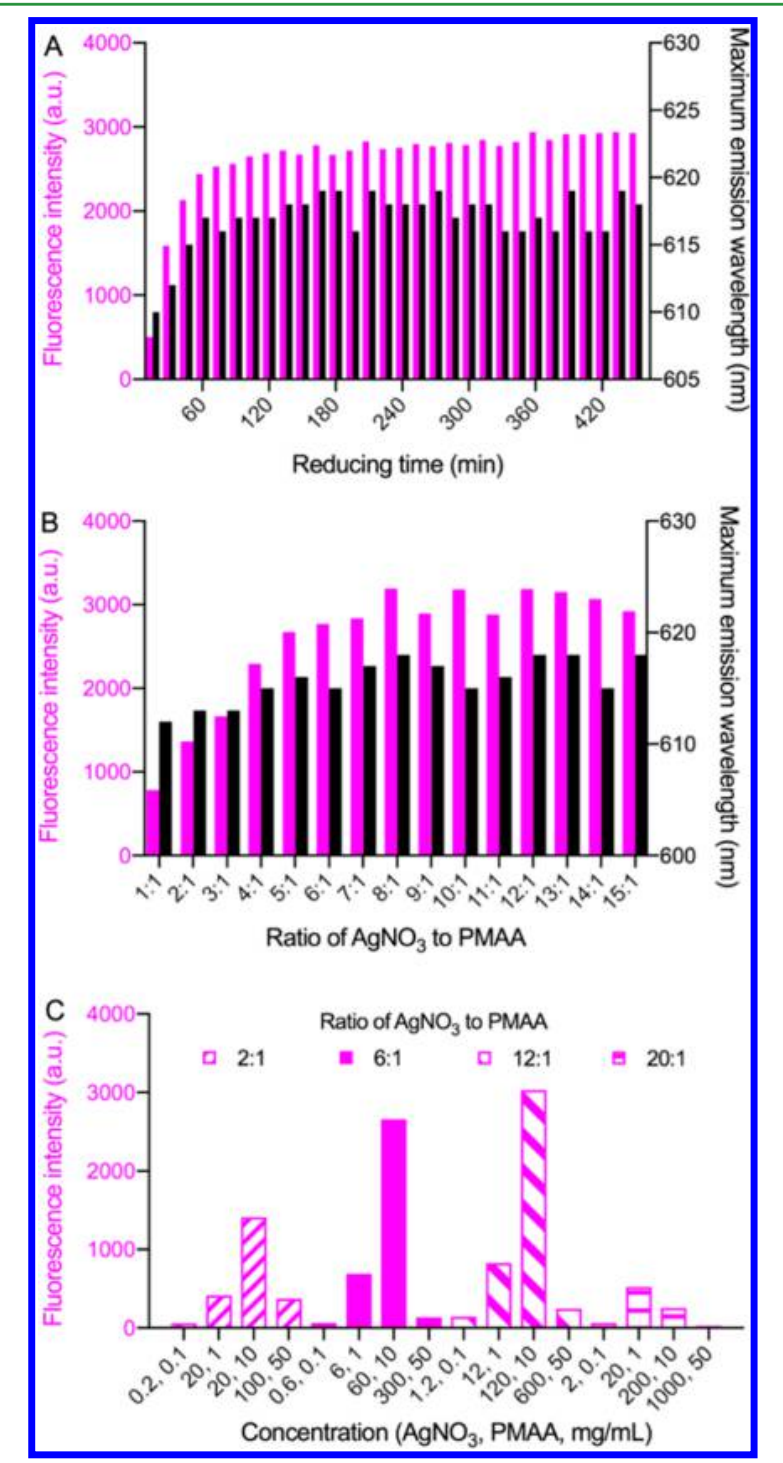

Figure 1. Optimization of AgNCs synthesis by varying UVA irradiation time, the $\mathrm{AgNO}_{3}$-to-PMAA ratios, and absolute concentrations of $\mathrm{AgNO}_{3}$ and PMAA. (A) Fluorescence intensity and the maximum emission wavelength of AgNCs formed with different UVA irradiation times. (B) Fluorescence intensity and maximum emission wavelength of $\mathrm{AgNCs}$ that were synthesized using $\mathrm{AgNO}_{3}$-to-PMAA ratios ranging from 1:1 to $15: 1\left(\mathrm{AgNO}_{3} / \mathrm{PMAA}\right)$. (C) Fluorescence intensities of $\mathrm{AgNCs}$ that were synthesized with different absolute concentrations of $\mathrm{AgNO}_{3}$ and PMAA at $\mathrm{AgNO}_{3}$-to-PMAA ratios of 2:1, 6:1, 12:1, and 20:1 ( $\left.\mathrm{AgNO}_{3} / \mathrm{PMAA}\right)$.

continuous formation of AgNCs, and after $60 \mathrm{~min}$ of UVA exposure, the fluorescence intensity reached a plateau, which indicated the saturation of the AgNCs formation. Further UVA irradiation did not cause a decrease in fluorescence, which verified the great photostability of the AgNCs. The wavelength of maximum emission underwent a red shift at the beginning of the AgNCs formation and then became stable, which corresponded to the formation and saturation of AgNCs. The synthesis of AgNCs was further achieved using other light sources, such as an $18 \mathrm{~W}$ linear light bulb and sunlight. The results indicated that the light bulb and sunlight could also 


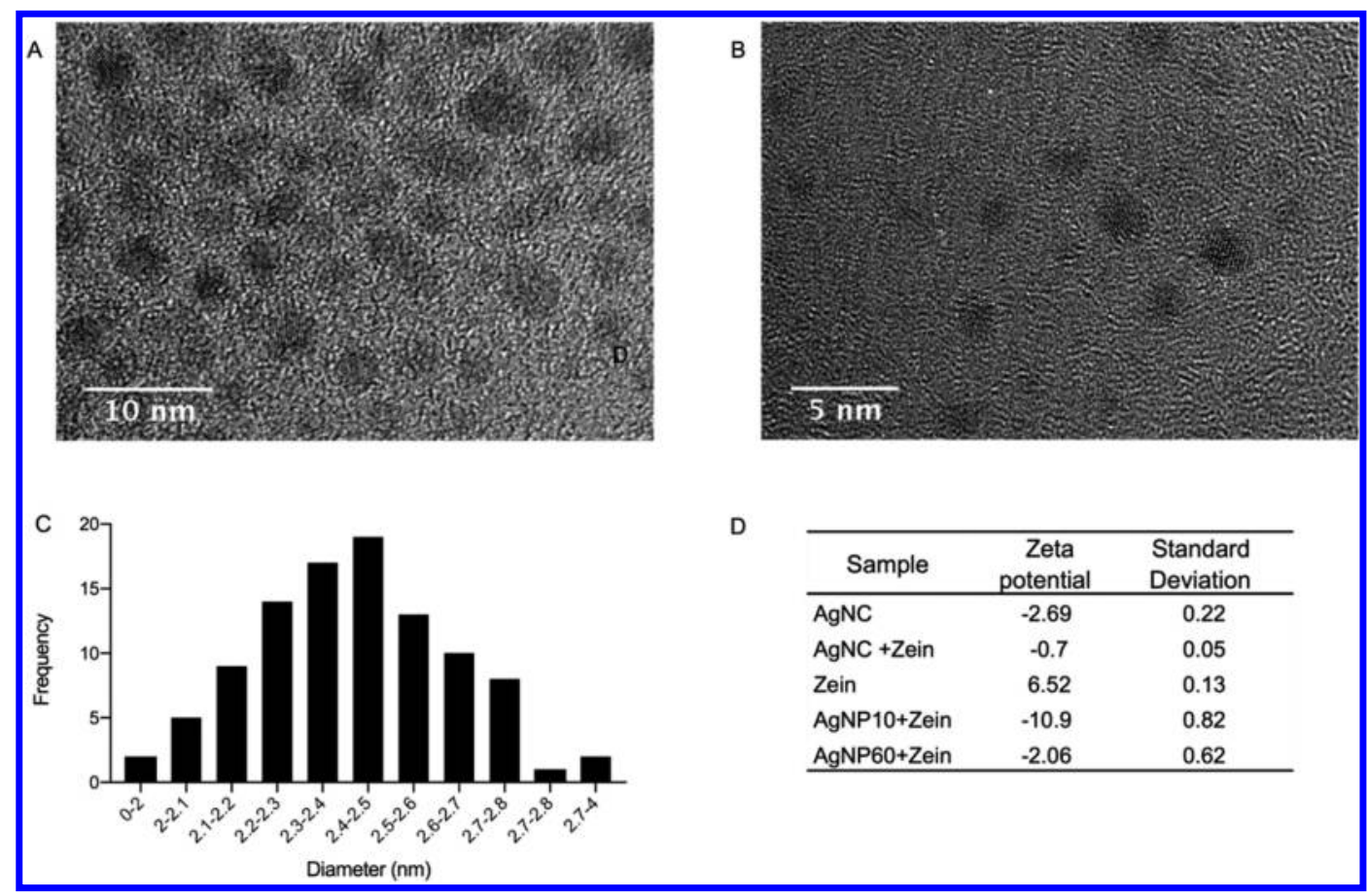

Figure 2. Characterization of AgNCs. (A) STEM images of AgNCs and (B) AgNCs in $0.1 \%$ zein and 70\% ethanol solution. (C) Size distribution of AgNCs $(n=100)$. (D) Zeta potential of AgNCs, zein, and mixtures of zein and AgNCs, zein and AgNP10, and zein and AgNP60.

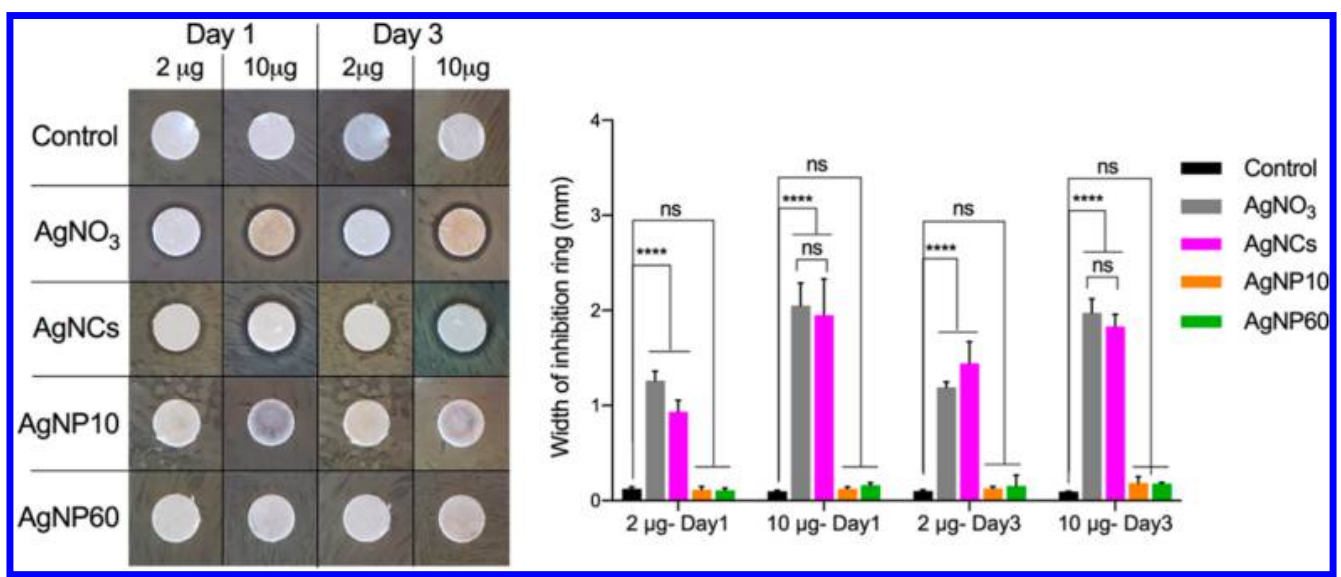

Figure 3. Agar diffusion test of different silver nanocomposite-embedded zein films. Left: Inhibition zone of E. coli $\mathrm{O} 157: \mathrm{H}_{7}$ treated by $\mathrm{AgNO}{ }_{3}$, AgNCs, AgNP10, and AgNP60 with $2 \mu \mathrm{g}$ and $10 \mu \mathrm{g}$ Ag equivalents, respectively, for 1 and 3 days. Right: the width of inhibition zone (****p< $0.0001, n s>0.9999, n=3)$.

reduce the $\mathrm{Ag}^{+}$and form AgNCs, but they were less effective than UVA irradiation (Figure S1).

PMAA plays a critical role in the synthesis of AgNCs. It carried carboxylic acid groups that are capable to coordinate with $\mathrm{Ag}^{+}$, and the hydrophobic regions in PMAA facilitated the formation of AgNCs. Further, the spatial structure prevented the aggregation of AgNCs. ${ }^{17,24}$ Thus, different concentration ratios of $\mathrm{AgNO}_{3}$ to PMAA ( $\mathrm{AgNO}_{3}$-to-PMAA ratios) were then tested with $60 \mathrm{~min}$ of UVA irradiation to optimize the conditions for the synthesis of AgNCs. Holding PMAA at 10 $\mathrm{mg} / \mathrm{mL}$ and increasing $\mathrm{AgNO}_{3}$-to-PMAA ratios initially enhanced the fluorescence intensity of AgNCs. However, a plateau was reached between ratios of $8: 1$ to $12: 1$, followed by a slight decrease (Figure 1B). This phenomenon indicated the nonlinear relationship between the $\mathrm{AgNO}_{3}$ to PMAA ratio and the fluorescence intensity of AgNCs. A similar trend was also observed when the PMAA concentration was fixed at $40 \mathrm{mg} /$
$\mathrm{mL}$; the fluorescence intensity of AgNCs increased and reached a maximum at $240 \mathrm{mg} / \mathrm{mL} \mathrm{AgNO}_{3}$, followed by a slight decrease (Figure S2).

In addition to the changes in $\mathrm{AgNO}_{3}$-to-PMAA ratios, changes of absolute concentrations of $\mathrm{AgNO}_{3}$ and PMAA were also found to affect the fluorescence properties of AgNCs. Thus, AgNCs were synthesized using a series of absolute concentrations of $\mathrm{AgNO}_{3}$ and PMAA under $\mathrm{AgNO}_{3}$-to-PMAA ratios of $2: 1,6: 1,12: 1$, and 20:1 (Figure 1C). Generally, with the same $\mathrm{AgNO}_{3}$-to-PMAA ratio, a higher concentration of these substrates produced a larger amount of AgNCs, resulting in higher fluorescence intensity. However, when the silver and PMAA concentration exceeded a threshold, the fluorescence intensity decreased significantly, indicating that a very high $\mathrm{AgNO}_{3}$ concentration may inhibit the formation of AgNCs. The concentrations of $\mathrm{AgNO}_{3}$ for optimal formation of AgNCs varied depending on the different $\mathrm{AgNO}_{3}$-to-PMAA ratios. 


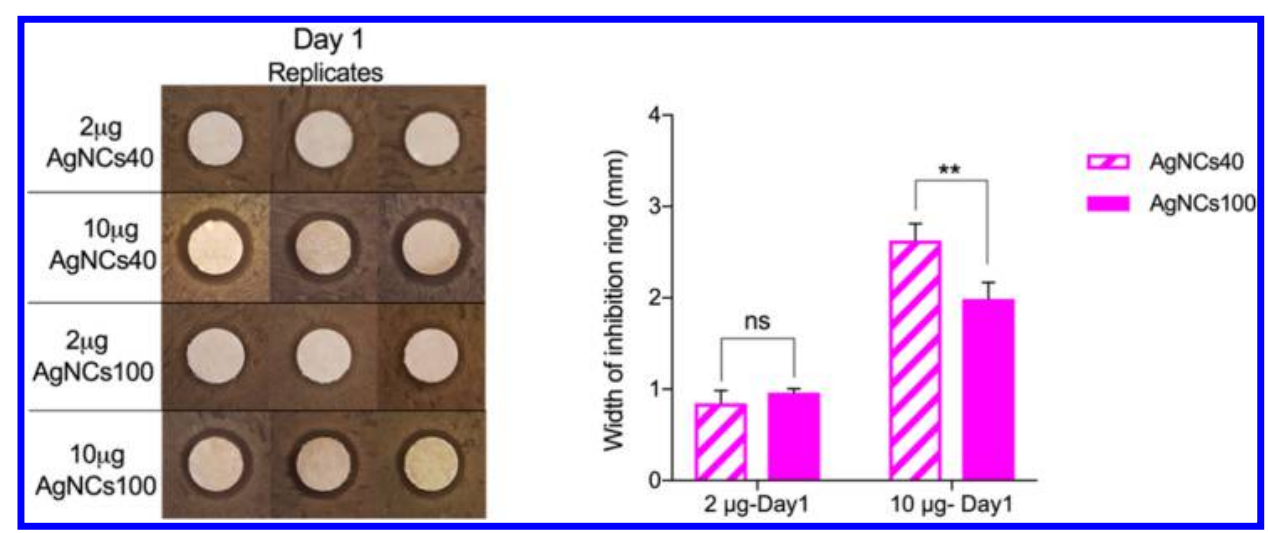

Figure 4. Agar diffusion test of zein films embedding AgNCs synthesized by 40 min (AgNC40) and 100 min (AgNC100) UVA irradiation. Left: Inhibition zone of E. coli O157:H7 treated with AgNC40 and AgNC100 at $2 \mu \mathrm{g}$ and $10 \mu \mathrm{g}$ Ag equivalents, respectively. Right: the width of inhibition rings $(* * p<0.01, n s>0.9999, n=3)$.

Furthermore, AgNCs formed by the series of concentrations of $\mathrm{AgNO}_{3}$ and PMAA, 12, $1 ; 120,10 ; 20,1$; and 200, $10\left(\mathrm{AgNO}_{3}\right.$, PMAA; $\mathrm{mg} / \mathrm{mL}$ ), developed a small amount of pink floccule likely containing AgNCs and PMAA, which was presumably caused by the high ratio of $\mathrm{AgNO}_{3}$ to PMAA, as well as the gel formation ability of PMAA. At very high concentrations of $\mathrm{AgNO}_{3}$ and PMAA, i.e. 600, 50 and 1000, $50\left(\mathrm{AgNO}_{3}, \mathrm{PMAA}\right.$ $\mathrm{mg} / \mathrm{mL}$ ), the $\mathrm{AgNO}_{3}$ was supersaturated and not well dissolved; no dramatic fluorescence emission was observed.

Based on the results of the synthesis method optimization, we determined to synthesize AgNCs by reducing $60 \mathrm{mg} / \mathrm{mL}$ $\mathrm{AgNO}_{3}$ and $10 \mathrm{mg} / \mathrm{mL}$ PMAA with 60 min UVA exposure for further study.

The characterization of AgNCs was performed by observing their morphology and surface charge. Under scanning transmission electron microscopy (STEM), AgNCs showed a narrow size distribution around 2.2-2.4 nm (Figures 2A, C) and were well dispersed (Figure S3A). After mixing AgNCs with zein in $70 \%$ ethanol, no significant changes in the size and dispersion of AgNCs were observed, which indicated that AgNCs were highly stable in the zein-containing $70 \%$ ethanol solution (Figures 2B, S3B). The zeta potential of AgNCs was -2.69 and $-0.70 \mathrm{mV}$ before and after mixing with zein solution, respectively. The mixture of zein and AgNP10, AgNP60 in 70\% ethanol presented zeta potentials of -10.9 and $-2.06 \mathrm{mV}$, respectively.

3.2. Potent Antimicrobial Activity Exhibited by AgNCs-Embedded Zein Film. The antimicrobial activity of AgNCs-embedded zein film was tested on pathogenic E. coli O157:H7 using both an agar diffusion test and a growth curve measurement. $\mathrm{AgNO}_{3}, \mathrm{AgNP} 10$, and AgNP60 were included as comparisons (Figure 3). In the agar diffusion test, silver composites of each kind (silver equivalents: $2 \mu \mathrm{g}$ and $10 \mu \mathrm{g}$, respectively) and zein ( $2.5 \mathrm{mg}$ ) were loaded on diffusion disks to test their antimicrobial activities. Diffusion disks loaded with $5 \mu \mathrm{L} \mathrm{TSB}, 1.7 \mu \mathrm{g}$ PMAA, and $2.5 \mathrm{mg}$ zein were used as the control.

After 1-day and 3-day treatments, no inhibition rings were observed in the control group, and some bacterial colonies were present on the agar plate on day 3 . After treating bacteria with 2 $\mu \mathrm{g}$ silver equivalents of $\mathrm{AgNCs}$ or $\mathrm{AgNO}_{3}$ for 1 day, clear inhibition zones of $0.93 \mathrm{~mm}$ and $1.26 \mathrm{~mm}$ widths were observed around the $\mathrm{AgNCs}$ and $\mathrm{AgNO}_{3}$ saturated disks, respectively. When bacteria were treated with $10 \mu \mathrm{g} \mathrm{Ag}$ equivalents of $\mathrm{AgNCs}$ and $\mathrm{AgNO}_{3}$ greater antimicrobial effects were observed, as indicated by inhibition zones of 1.95 and 2.05 $\mathrm{mm}$, respectively. There was no significant difference between the width of inhibition rings after 1-day or 3-day treatments of $\mathrm{AgNO}_{3}$ and $\mathrm{AgNCs}$ with $10 \mu \mathrm{g} \mathrm{Ag}$ equivalents, which verified the comparable antimicrobial activities of $\mathrm{AgNO}_{3}$ and $\mathrm{AgNCs}$. Moreover, as expected, the inhibition activities of both $\mathrm{AgNO}_{3}$ and AgNCs were concentration-dependent. However, no clear inhibition rings were observed in bacteria treated by AgNP10 or AgNP60 of $2 \mu \mathrm{g}$ or $10 \mu \mathrm{g}$ silver equivalents, and there was no significant difference in inhibition zones between AgNP10 or AgNP60 treated groups and the control group.

These results can be explained by both the high surface to volume ratio and high mobility of AgNCs relative to those of AgNPs. The higher surface to volume ratio of AgNCs results in greater surface contact with bacteria and consequently higher antimicrobial activity. The greater mobility of silver nanocomposites is another key factor that contributes to improved antimicrobial activity. Specifically, the antimicrobial activity can be influenced by the release rate of $\mathrm{Ag}$ from different silver nanocomposites that were embedded in zein films. Thus, we studied the release rate of Ag from these films by submerging different silver nanocomposite-embedded zein films in water and testing $\mathrm{Ag}$ concentrations in the surrounding water every half day. We observed that AgNP10 and AgNP60 embedded zein films released $\mathrm{Ag}$ at the slowest rate, whereas both AgNCsembedded zein film and $\mathrm{AgNO}_{3}$ steadily released $\mathrm{Ag}$ at a much faster rate (Figure S4). This result corresponded to the weak antimicrobial activity of AgNP10 and AgNP60 and the potent antimicrobial activity of $\mathrm{AgNCs}$ and $\mathrm{AgNO}_{3}$. To determine whether zein films inhibited the mobility of AgNP10 and AgNP60, we performed agar diffusion tests for bare AgNCs, AgNP10, AgNP60, and $\mathrm{AgNO}_{3}$ (no zein coating) at $10 \mu \mathrm{g}$ silver equivalents. The antimicrobial efficacies were similar to those with zein coatings, and no clear antimicrobial activity was observed for AgNP10 or AgNP60 (data not shown). We also examined the agar diffusion test for large AgNPs with diameters of $550 \mathrm{~nm}$ (AgNP550) (Figure S5). Again, no clear bacteria inhibition zone was observed with $50 \mu \mathrm{g}$ AgNP550 treated for 1 day.

Figure 4 shows the effect of UVA irradiation time $(40 \mathrm{~min}$, AgNC40 and $100 \mathrm{~min}, \mathrm{AgNC} 100)$ during AgNCs synthesis on antimicrobial activity assessed by agar diffusion tests at $2 \mu \mathrm{g}$ and $10 \mu \mathrm{g} \mathrm{Ag}$ equivalents. After 1-day bacterial treatment, AgNC100 (2 $\mu \mathrm{g} \mathrm{Ag}$ equivalents) showed a clear inhibition zone of $1.98 \mathrm{~mm}$ width, which was comparable to that observed 


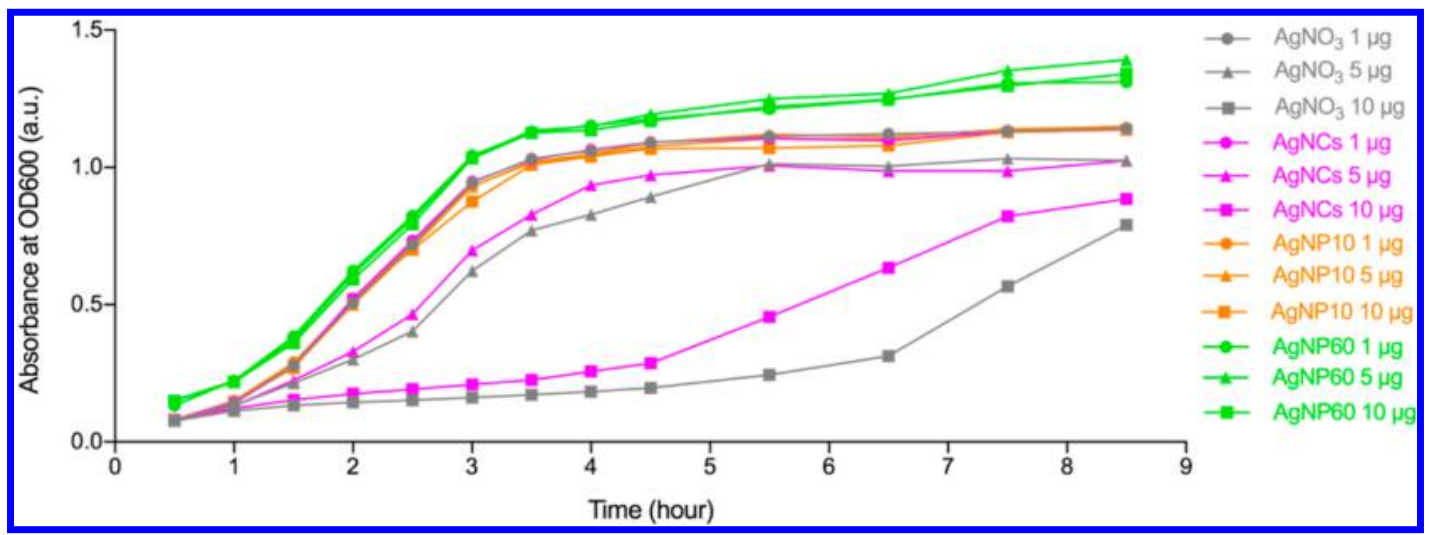

Figure 5. Growth curve of E. coli O157:H7 treated with different silver nanocomposites. E. coli were incubated in tryptic soy broth with $\mathrm{AgNO}_{3}$ (gray), AgNCs (pink), AgNP10 (orange), and AgNP60 (green) at concentrations of $1(\bullet), 5(\boldsymbol{\Delta})$, and $10(\boldsymbol{\square}) \mu \mathrm{g} / \mathrm{mL}$ Ag equivalents, respectively.

for AgNCs with $10 \mu \mathrm{g}$ Ag equivalents synthesized using $60 \mathrm{~min}$ UVA irradiation $(1.95 \mathrm{~mm})$. The widest inhibition zone, measuring $2.62 \mathrm{~mm}$, was observed for AgNC40 with $10 \mu \mathrm{g} \mathrm{Ag}$ equivalents, which was significantly larger than that for AgNC100 (10 $\mu \mathrm{g}$ Ag equivalents). However, no significant difference was observed between the inhibition rings treated by AgNC40 and AgNC100 with $10 \mu \mathrm{g}$ Ag equivalents after 5 days (Figure S6). Nor was there any significant difference observed between the inhibition rings for AgNC40 and AgNC100 at $2 \mu \mathrm{g}$ $\mathrm{Ag}$ equivalents for either 1-day or 5-day treatments. These results indicate that the reducing time is not an important factor contributing to the antimicrobial effect of AgNCs.

The growth curves showing the absorbance at $600 \mathrm{~nm}$ for $E$. coli $\mathrm{O} 157: \mathrm{H} 7$ cultures treated with bare $\mathrm{AgNCs}, \mathrm{AgNO}_{3}$, AgNP10, and AgNP60 at 1, 5, and $10 \mu \mathrm{g} / \mathrm{mL} \mathrm{Ag}$ equivalents, respectively are shown in Figure 5. At concentrations of 1 and 5 $\mu \mathrm{g} / \mathrm{mL} \mathrm{Ag} \mathrm{equivalents,} \mathrm{AgNCs} \mathrm{exhibited} \mathrm{comparable} \mathrm{anti-}$ microbial activity to $\mathrm{AgNO}_{3}$. At the concentration of $10 \mu \mathrm{g} / \mathrm{mL}$ $\mathrm{Ag}$ equivalent, a longer lag phase $(5.5 \mathrm{~h})$ was observed for $\mathrm{AgNO}_{3}$-treated E. coli than for AgNCs-treated E. coli $(4 \mathrm{~h})$. However, after $8 \mathrm{~h}$ of growth, both $\mathrm{AgNO}_{3}$-treated and AgNCstreated $E$. coli reached the stationary phase, and the maximum cell densities of two treatments were comparable. In addition, a longer generation time and lower maximum cell density were observed for E. coli O157:H7 treated by $\mathrm{AgNO}_{3}$ and AgNCs at 5 and $10 \mu \mathrm{g} / \mathrm{mL} \mathrm{Ag}$ than for E. coli cells treated with AgNP10 and AgNP60. While $\mathrm{AgNO}_{3}$ and AgNCs showed concentration-dependent antimicrobial activity, AgNP10 and AgNP60 showed no antimicrobial efficacy even at a concentration as high as $10 \mu \mathrm{g} / \mathrm{mL} \mathrm{Ag}$. This result was consistent with the agar diffusion test results and release profiles of zein films embedding different silver nanocomposites (Figure S4).

Moreover, to mimic the actual antimicrobial performance of this coating, different silver nanocomposite-embedded zein films were coated on the nutrient agar, followed by inoculating bacteria to test the MIC. The MICs of silver for AgNCs, $\mathrm{AgNO}_{3}, \mathrm{AgNP} 10$, and AgNP60 were 1.05, 0.525, 134.4, and $201.6 \mu \mathrm{g} / \mathrm{cm}^{2}$, respectively. Consistent with the previous assay, these results further supported our findings on the antimicrobial efficacies of these Ag nanocomposites.

3.3. Low Cytotoxicity of AgNCs to Human Cells. The viability of human colon cancer cells of cell line HCT116 after treatment with different silver nanocomposites for $48 \mathrm{~h}$ at 37 ${ }^{\circ} \mathrm{C}$ is shown in Figure 6 . The results of the cytotoxicity study indicate that AgNCs are significantly less cytotoxic than $\mathrm{AgNO}_{3}$. At a $\mathrm{Ag}$ concentration of $10 \mu \mathrm{g} / \mathrm{mL}, \mathrm{AgNC}$ treated

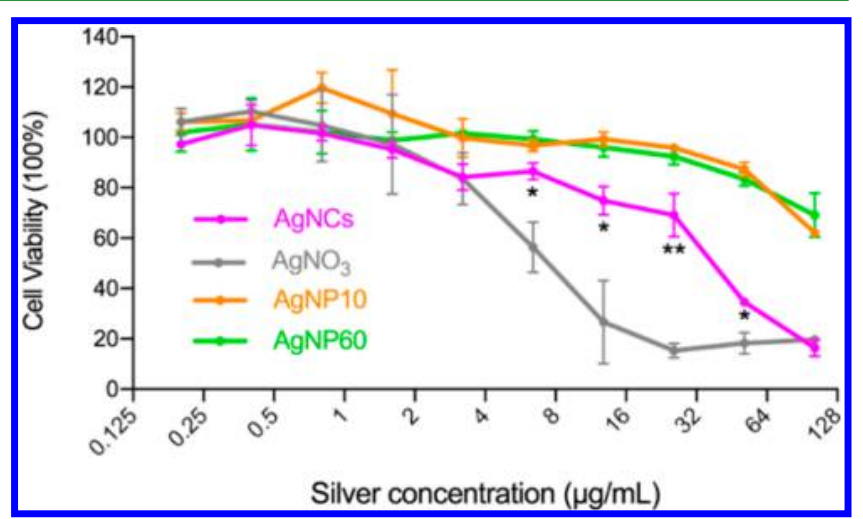

Figure 6. Cell viability of HCT116 human colon cancer cells treated with AgNCs (pink), $\mathrm{AgNO}_{3}$ (gray), AgNP10 (orange), and AgNP60 (green). Asterisks represent the significant differences between the cell viabilites for $\mathrm{AgNC}$ and $\mathrm{AgNO}_{3}$ treatments at the same $\mathrm{Ag}$ concentration $(* * p<0.01, * p<0.05, n=3)$.

cells showed $80 \%$ viability, whereas the survival rate for $\mathrm{AgNO}_{3}$ treated cells was only $20 \%$. The $\mathrm{IC}_{50}$ for AgNCs was $34.68 \mu \mathrm{g} /$ $\mathrm{mL}$, in contrast to $9.14 \mu \mathrm{g} / \mathrm{mL}$ for $\mathrm{AgNO}_{3} . \mathrm{AgNP} 10$ and AgNP60 showed less toxicity than both AgNCs and $\mathrm{AgNO}_{3}$, and this was possibly caused by the same reasons for their lower antimicrobial efficacy, namely, the lower mobility, slower cell membrane penetration, and inefficient silver release of silver nanoparticles.

\section{CONCLUSIONS}

In summary, we developed a novel antimicrobial coating material by embedding antimicrobial AgNCs into zein films. The fluorescence of AgNCs depended on the UVA irradiation time, light sources, concentration ratio of $\mathrm{AgNO}_{3}$ to PMAA, and absolute concentrations of $\mathrm{AgNO}_{3}$ and PMAA. The antimicrobial efficacy and toxicity of AgNCs were systematically evaluated and compared with those of $\mathrm{AgNO}_{3}, \mathrm{AgNP} 10$, and AgNP60. AgNCs presented comparable dose-dependent antimicrobial efficacy to $\mathrm{AgNO}_{3}$, but with significantly lower toxicity toward human cells than $\mathrm{AgNO}_{3}$. Further, AgNCs presented much greater antimicrobial capacity than AgNP10 and AgNP60, which indicates that the administration dose of AgNCs for antimicrobial applications could be dramatically reduced compared to that of AgNPs. Overall, the study indicated that the low toxicity, low volatilization, and ultrasmall size of AgNCs enhanced their antimicrobial properties and that 
the AgNC-embedded zein film is promising antimicrobial coating material for food packaging.

\section{ASSOCIATED CONTENT}

\section{S Supporting Information}

The Supporting Information is available free of charge on the ACS Publications website at DOI: 10.1021/acsami.7b08152.

Fluorescence intensity of AgNCs reduced by different light sources; effect of concentration ratios of $\mathrm{AgNO}_{3}$ to PMAA on the fluorescent intensity of AgNCs with fixed PMAA concentration of $40 \mathrm{mg} / \mathrm{mL}$; TEM images of AgNCs before and after coating by zein protein; release profile of $\mathrm{Ag}$ from zein films embedding $\mathrm{AgNCs}, \mathrm{AgNO}_{3}$, AgNP10, and AgNP60; agar diffusion test of zein films embedding AgNCs, $\mathrm{AgNO}_{3}$, and AgNP550 on E. coli; agar diffusion test of zein films embedding AgNCs40 and AgNCs100 on E. coli (PDF)

\section{AUTHOR INFORMATION}

\section{Corresponding Authors}

*E-mail: wangqin@umd.edu. Tel: (301) 405-8421 (Q.W.).

*E-mail: chen_xianggui@mail.xhu.edu.cn. Tel: +86 (028) 8772-0550 (X.C. .).

ORCID

Jinglin Zhang: 0000-0002-5058-9488

Ying Li: 0000-0001-6622-2915

Qin Wang: 0000-0002-7496-3921

\section{Author Contributions}

L.M. designed this work and performed most experiments, analyzed and interpreted data, and drafted and revised the manuscript. Z.T. designed experiments and revised the manuscript. G.Z. participated in the conception and design of the work, analyzed data, and performed the zeta potential test. Y.L. performed the ICP test for the releasing profile. F.Z. designed experiments and participated in the synthesis of AgNCs. J.Z. designed experiments and participated in the cell viability test. Y.L. designed experiments and participated in the synthesis of AgNCs. Y.G. participated in the TEM imaging and revised the manuscript. Y.L., X.C., and Q.W. supervised all studies, interpreted data, and wrote the manuscript.

\section{Notes}

The authors declare no competing financial interest.

\section{ACKNOWLEDGMENTS}

This work was supported by the Maryland Agricultural Experiment Station (MAES) under the Project Number MD711 and the USDA National Institute of Food and Agriculture (No: 2014-67021-21585). The authors are grateful for the technical support of the Maryland NanoCenter of the University of Maryland in Transmission electron microscopy.

\section{REFERENCES}

(1) Kim, Y.-T.; Kim, K.; Han, J. H.; Kimmel, R. M. In Smart Packaging Technologies for Fast Moving Consumer Goods; Karry, J., Butler, P., Eds.; Wiley: Chichester, SXW, 2008; Chapter 6, pp 99-110.

(2) Echegoyen, Y.; Nerín, C. Nanoparticle Release from Nano-Silver Antimicrobial Food Containers. Food Chem. Toxicol. 2013, 62, 16-22.

(3) Kumar, A.; Vemula, P. K.; Ajayan, P. M.; John, G. SilverNanoparticle-Embedded Antimicrobial Paints Based on Vegetable Oil. Nat. Mater. 2008, 7, 236-241.

(4) Monteiro, D. R.; Gorup, L. F.; Takamiya, A. S.; Ruvollo-Filho, A. C.; de Camargo, E. R.; Barbosa, D. B. The Growing Importance of
Materials that Prevent Microbial Adhesion: Antimicrobial Effect of Medical Devices Containing Silver. Int. I. Antimicrob. Agents 2009, 34, 103-110.

(5) Maneerung, T.; Tokura, S.; Rujiravanit, R. Impregnation of Silver Nanoparticles into Bacterial Cellulose for Antimicrobial Wound Dressing. Carbohvdr. Polvm. 2008, 72, 43-51.

(6) Sharma, V. K.; Yngard, R. A.; Lin, Y. Silver Nanoparticles: Green Synthesis and Their Antimicrobial Activities. Adv. Colloid Interface Sci. 2009, 145, 83-96.

(7) Carlson, C.; Hussain, S. M.; Schrand, A. M.; Braydich-Stolle, L. K.; Hess, K. L.; Jones, R. L.; Schlager, J. J. Unique Cellular Interaction of Silver Nanoparticles: Size-dependent Generation of Reactive Oxygen Species. I. Phvs. Chem. B 2008, 112, 13608-13619.

(8) Martinez-Castanon, G.; Nino-Martinez, N.; Martinez-Gutierrez, F.; Martinez-Mendoza, J.; Ruiz, F. Synthesis and Antibacterial Activity of Silver Nanoparticles with Different Sizes. I. Nanopart. Res. 2008, 10, 1343-1348.

(9) Morones, J. R.; Elechiguerra, J. L.; Camacho, A.; Holt, K.; Kouri, J. B.; Ramírez, J. T.; Yacaman, M. J. The Bactericidal Effect of Silver Nanoparticles. Nanotechnology 2005, 16, 2346-2353.

(10) Wakshlak, R. B.-K.; Pedahzur, R; Avnir, D. Antibacterial Activity of Silver-Killed Bacteria: the "Zombies" Effect. Sci. Rep. 2015, 5, 9555-9599.

(11) Gao, P.; Nie, X.; Zou, M.; Shi, Y.; Cheng, G. Recent Advances in Materials for Extended-Release Antibiotic Delivery System. L. Antibiot. 2011, 64, 625-634.

(12) Richter, A. P.; Brown, J. S.; Bharti, B.; Wang, A.; Gangwal, S.; Houck, K.; Hubal, E. A. C.; Paunov, V. N.; Stoyanov, S. D.; Velev, O. D. An Environmentally Benign Antimicrobial Nanoparticle Based on a Silver-Infused Lignin Core. Nat. Nanotechnol. 2015, 10, 817-823.

(13) Chinnapongse, S. L.; MacCuspie, R. I.; Hackley, V. A. Persistence of Singly Dispersed Silver Nanoparticles in Natural Freshwaters, Synthetic Seawater, and Simulated Estuarine Waters. Sci. Total Environ. 2011, 409, 2443-2450.

(14) Stern, S. T.; McNeil, S. E. Nanotechnology Safety Concerns Revisited. Toxicol. Sci. 2008, 101, 4-21.

(15) Yuan, X.; Setyawati, M. I.; Tan, A. S.; Ong, C. N.; Leong, D. T.; Xie, J. Highly Luminescent Silver Nanoclusters with Tunable Emissions: Cyclic Reduction-Decomposition Synthesis and Antimicrobial Properties. NPG Asia Mater. 2013, 5, e39.

(16) Laaksonen, T.; Ruiz, V.; Liljeroth, P.; Quinn, B. M. Quantised Charging of Monolayer-Protected Nanoparticles. Chem. Soc. Rev. 2008, 37, $1836-1846$.

(17) Wang, X.; Xu, S.; Xu, W. Synthesis of highly stable fluorescent $\mathrm{Ag}$ nanocluster@ polymer nanoparticles in aqueous solution. Nanoscale 2011, 3, 4670-4675.

(18) Díez, I.; Ras, H. A. R. Fluorescent silver nanoclusters. Nanoscale 2011, 3, 1963-1970.

(19) Zhang, L.; Zhu, J.; Guo, S.; Li, T.; Li, J.; Wang, E. K. Photoinduced Electron Transfer of DNA/Ag Nanoclusters Modulated by G-quadruplex/hemin Complex for the Construction of Versatile Biosensors. I. Am. Chem. Soc. 2013, 135, 2403-2406.

(20) Wang, Y.; Dai, C.; Yan, X. P. Fabrication of Folate Bioconjugated Near-infrared Fluorescent Silver Nanoclusters for Targeted in vitro and in vivo Bioimaging. Chem. Commun. 2014, 50, 14341-14344.

(21) Dadmehr, M.; Hosseini, M.; Hosseinkhani, S.; Ganjali, M. R.; Sheikhnejad, R. Label Free Colorimetric and Fluorimetric Direct Detection of Methylated DNA Based on Silver Nanoclusters for Cancer Early Diagnosis. Biosens. Bioelectron. 2015, 73, 108-113.

(22) Zhao, J.; Millians, W.; Tang, S.; Wu, T.; Zhu, L.; Ming, W. SelfStratified Antimicrobial Acrylic Coatings via One-Step UV Curing. ACS Appl. Mater. Interfaces 2015, 7, 18467-18472.

(23) Javani, S.; Lorca, R.; Latorre, A.; Flors, C.; Cortajarena, A. L.; Somoza, Á. Antibacterial Activity of DNA-Stabilized Silver Nanoclusters Tuned by Oligonucleotide Sequence. ACS Appl. Mater. Interfaces 2016, 8, 10147-10154. 
(24) Shang, L.; Dong, S. Silver Nanocluster-Based Fluorescent Sensors for Sensitive Detection of Cu (II). L. Mater. Chem. 2008, 18, $4636-4640$.

(25) Zhang, Y.; Niu, Y.; Luo, Y.; Ge, M.; Yang, T.; Yu, L. L.; Wang, Q. Fabrication, Characterization and Antimicrobial Activities of Thymol-loaded Zein Nanoparticles Stabilized by Sodium Caseinatechitosan Hydrochloride Double Layers. Food Chem. 2014, 142, 269275.

(26) Moradi, M.; Tajik, H.; Rohani, S. M.; Mahmoudian, A. Antioxidant and Antimicrobial Effects of Zein Edible Film Impregnated with Zataria Multiflora Boiss. Essential Oil and Monolaurin. Lebensm. Wiss. Technol. 2016, 72, 37-43.

(27) Kashiri, M.; Cerisuelo, J. P.; Domínguez, I.; López-Carballo, G.; Muriel-Gallet, V.; Gavara, R.; Hernández-Muñoz, P. Zein Films and Coatings as Carriers and Release Systems of Zataria Multiflora Boiss. Essential Oil for Antimicrobial Food Packaging. Food Hvdrocolloids 2017, 70, 260-268.

(28) Ruparelia, J. P.; Chatterjee, A. K.; Duttagupta, S. P.; Mukherji, S. Strain Specificity in Antimicrobial Activity of Silver and Copper Nanoparticles. Acta Biomater. 2008, 4, 707-716. 


\section{Supporting Information}

\section{Silver nanoclusters-embedded zein films as}

\section{antimicrobial coating materials for food packaging}

Lei Mei ${ }^{1}$, Zi Teng ${ }^{1}$, Guizhi Zhu ${ }^{2}$, Yijing Liu' ${ }^{2}$, Fuwu Zhang ${ }^{2}$, Jinglin Zhang ${ }^{1}$, Ying Li $^{1}$, Yongguang Guan', Yaguang Luo ${ }^{3}$, Xianggui Chen ${ }^{4 *}$, Qin Wang ${ }^{\text {* }}$

1. Department of Nutrition and Food Science, College of Agriculture and Natural Resources, University of Maryland, College Park, Maryland 20742, United States.

2. Laboratory of Molecular Imaging and Nanomedicine, National Institute of Biomedical Imaging and Bioengineering (NIBIB), National Institutes of Health (NIH), Bethesda, Maryland 20814, United States.

3. Environmental Microbial and Food Safety Laboratory, USDA-ARS, 10300 Baltimore Ave., Bldg. 002, Beltsville, MD 20705, United States

4. School of Food and Bioengineering, Xihua University, Chengdu, Sichuan 610039, China.

*Corresponding author:

1. Qin Wang, Associate Professor

Department of Nutrition \& Food Science

University of Maryland College Park

3106 Skinner Building 
College Park, MD 20742

Phone: (301) 405-8421

E-mail: wangqin@umd.edu

2. Xianggui Chen, Professor

School of food and bioengineering

Xihua University

Chengdu, Sichuan 610039, China

Phone: +86 (028) 8772-0550

E-mail: chen_xianggui@mail.xhu.edu.cn

Table of content

1. Materials and methods.

2. Fluorescence of silver nanoclusters (AgNCs) reduced by different light sources.

3. Effect of concentration ratios of $\mathrm{AgNO}_{3}$ to poly methacrylic acid (PMAA) on the fluorescent intensity of AgNCs with fixed PMAA concentration of $40 \mathrm{mg} / \mathrm{mL}$.

4. Transmission electron microscopy (TEM) images of AgNCs before and after mixing with zein.

5. Release profile of silver from zein films embedding $\mathrm{AgNCs}, \mathrm{AgNO}_{3}$, silver nanoparticles with diameters of $10 \mathrm{~nm}(\mathrm{AgNP10})$ and $60 \mathrm{~nm}(\mathrm{AgNP60})$.

6. Agar diffusion test of zein films embedding silver nanoparticles with diameter of 550nm (AgNP550) on E. coli cells.

7. Agar diffusion test of zein films embedding silver nanoclusters synthesized by 40 min UVA (AgNCs40) radiation and 100 min UVA radiation (AgNCs100) on E. coli cells. 


\section{Materials and methods.}

\section{Materials}

$\mathrm{AgNO}_{3}$ (VWR International, Radnor, Pennsylvinia, USA) and PMAA (PMAA, Polysciences, Inc, Warrington, USA) were used to synthesize AgNCs. AgNP10 and AgNP60 were purchased from Alfa Aesar (Haverhill, Massachusetts, USA). AgNP550 was synthesized through reducing $\mathrm{AgNO}_{3}$ (VWR International, Radnor, Pennsylvinia, USA) by sodium borohydride (VWR International, Radnor, Pennsylvinia, USA). Zein protein was purschased from MP Biomedicals (Santa Ana, California, USA), and ethyl alcohol (ACS grade) was produced from PharmcoAaper (Shelbyville, Kentuchy, USA).

\section{Synthesis of AgNCs by sunlight and lamp light.}

AgNCs were synthesized by reducing $\mathrm{AgNO}_{3}$ under UVA radiation with a stabilizer PMAA. Briefly, $60 \mathrm{mg} / \mathrm{mL} \mathrm{AgNO}_{3}$ and $10 \mathrm{mg} / \mathrm{mL}$ PMAA were mixed and exposed to sunlight for 40 hours or to lamp light for 30 hours.

\section{Release profile of silver from zein film}

AgNCs was synthesized by reducing $60 \mathrm{mg} / \mathrm{mL} \mathrm{AgNO}_{3}$ and $10 \mathrm{mg} / \mathrm{mL}$ PMAA with UVA light for $60 \mathrm{~min}$, and then mixed with ethanol in ratio of 3:7 (v/v). Zein protein was dissolved in $70 \%$ ethanol. Zein solution at concentration of $10 \%$ were then mixed with $100 \mu \mathrm{g} / \mathrm{mL}$ AgNCs, AgNP10, AgNP60, and $\mathrm{AgNO}_{3}$. Later, $1 \mathrm{~mL}$ of each mixture were casted and dried into film. The casted films were then immersed in $20 \mathrm{~mL}$ water in dark for 3 days, and every half day $1 \mathrm{~mL}$ of surrounding solution was collected. The collected solution samples were diluted with 5\% nitric acid and measured for Ag concentration by ICP (5000 ICP-OES, Agilent Technologies, Santa Clara, California, USA). 


\section{Synthesis of silver nanoparticles.}

AgNP550 were synthesized by reducing $\mathrm{AgNO}_{3}$ with sodium borohydride. To be specific, $0.01 \mathrm{mM} \mathrm{NaBH}_{4}$ were dropped into $0.25 \mathrm{mM} \mathrm{AgNO}_{3}$ followed by vigorous shake. The mixture was then heated up to boiling temperature for $1 \mathrm{~h}$ to remove unreacted $\mathrm{NaBH}_{4}$. The synthesized AgNP550 were then dialyzed and refrigerated.

\section{Fluorescence of $\mathrm{AgNCs}$ reduced by different light sources.}

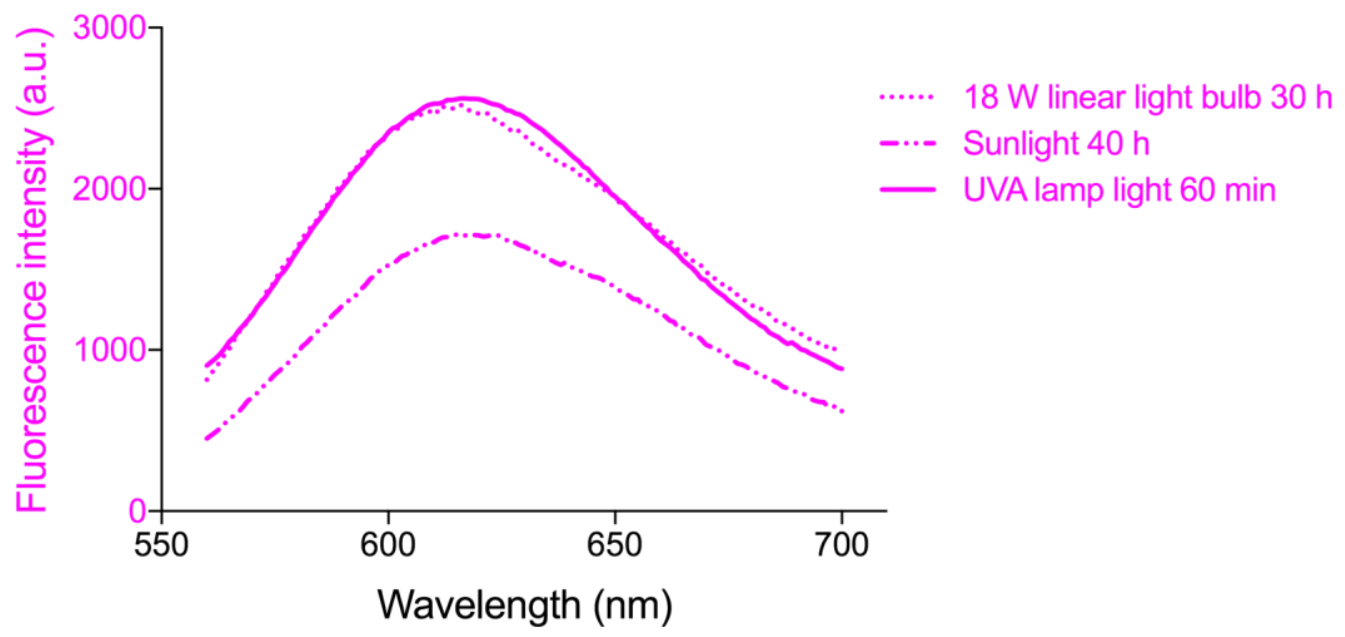

Figure S1. AgNCs synthesized by $40 \mathrm{~h}$ sunlight, $30 \mathrm{~h}$ linear light bulb light and $60 \mathrm{~min}$ UVA lamp light.

3. Effect of concentration ratios of $\mathrm{AgNO}_{3}$ to PMAA on the fluorescence of $\mathrm{AgNCs}$ with fixed PMAA concentration of $40 \mathrm{mg} / \mathrm{mL}$. 


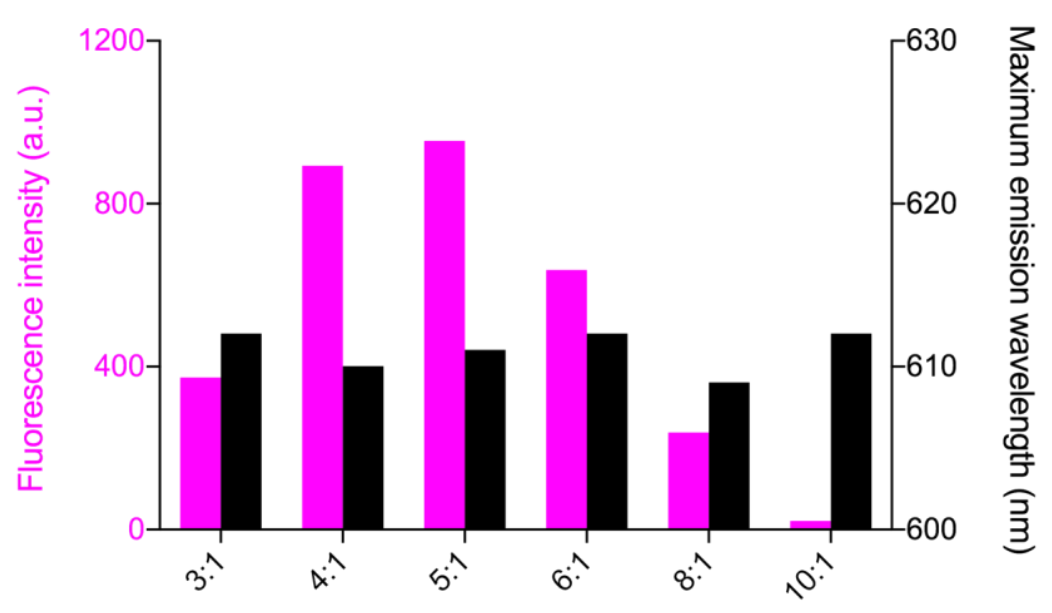

Figure S2. Fluorescence intensity of AgNCs synthesized with different concentration ratios of $\mathrm{AgNO}_{3}$ to PMAA with fixed PMAA concentration of $40 \mathrm{mg} / \mathrm{mL}$.

4. TEM of AgNCs before and after mixing with zein.
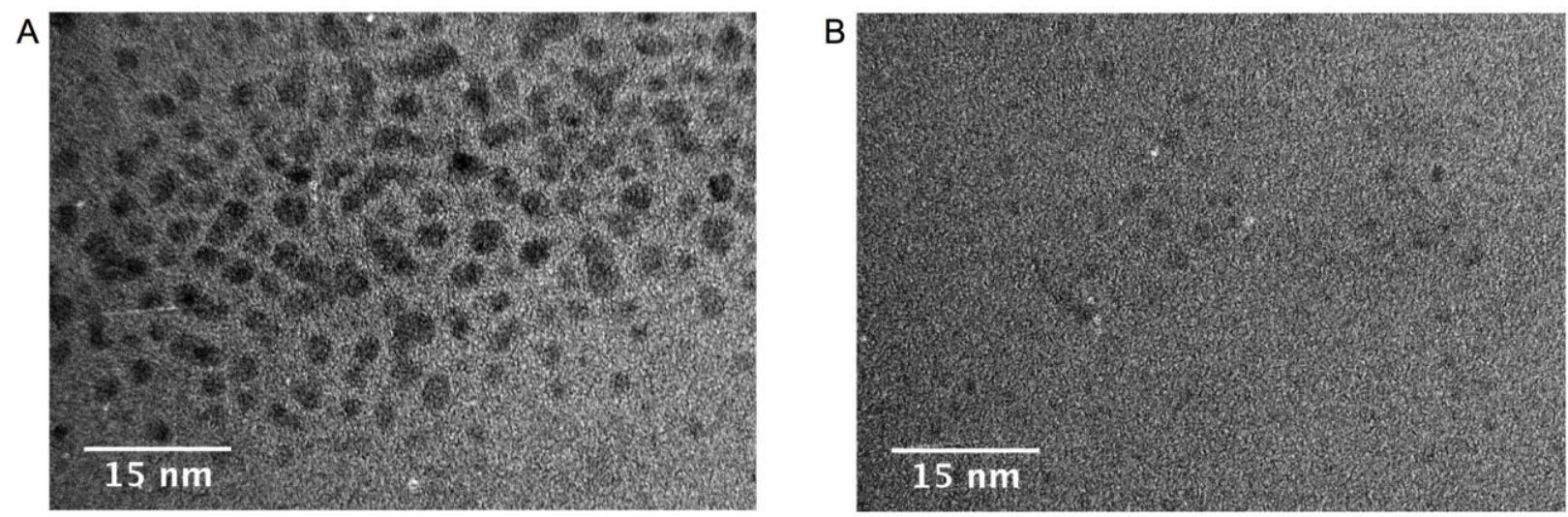

Figure S3. STEM images of AgNCs before (A) and after (B) mixing with zein.

5. Release profile of silver from zein films embedding AgNCs, $\mathrm{AgNO}_{3}, \mathrm{AgNP10}_{\text {, and }}$ AgNP60. 


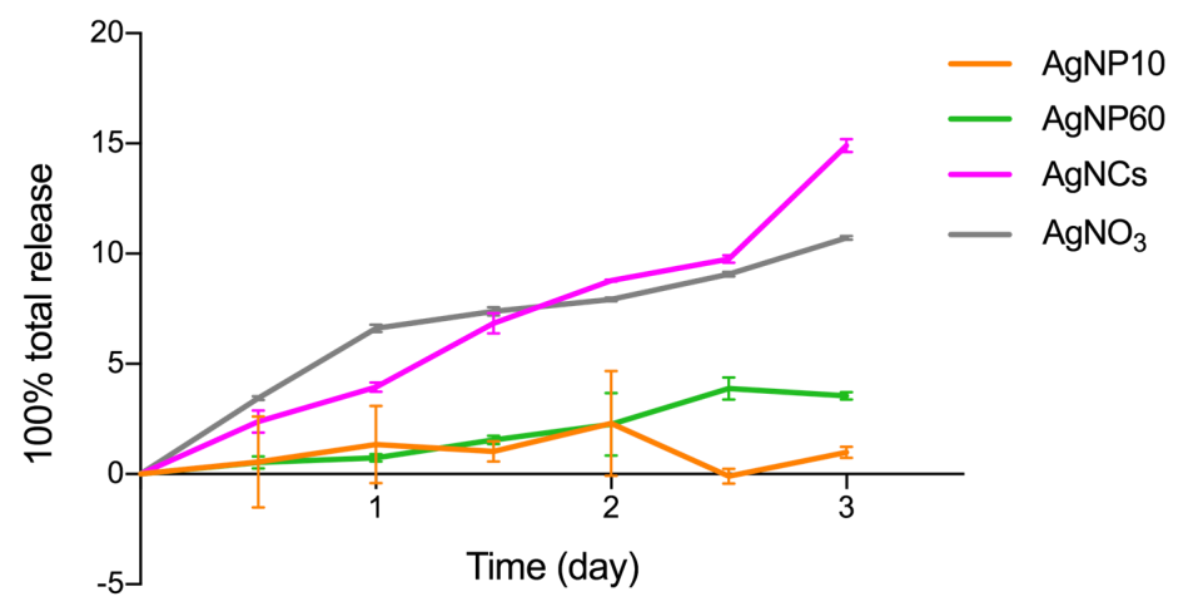

Figure S4. Releasing profile of $\mathrm{AgNCs}, \mathrm{AgNO}_{3}, \mathrm{AgNP} 10$, and $\mathrm{AgNP} 50$ embedded zein films submerged in water.

6. Agar diffusion test of AgNPs550 embedded zein films on E. coli cells.
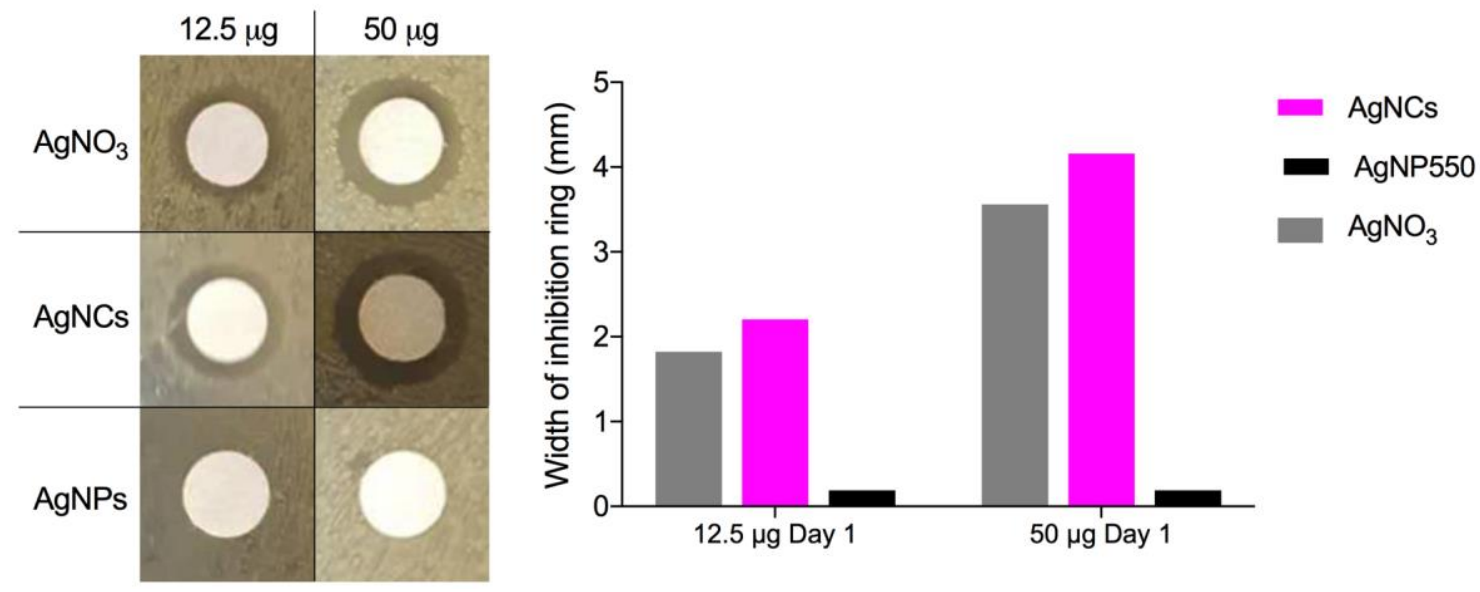

Figure S5. Inhibition ring of zein film embedding $\mathrm{AgNCs}, \mathrm{AgNO}_{3}$, and $\mathrm{AgNP550}$. Left:

Inhibition zone of E. coli treated by $12.5 \mu \mathrm{g}$ and $50 \mu \mathrm{g} \mathrm{AgNCs,} \mathrm{AgNO}_{3}$, and $\mathrm{AgNP} 550$ for 1 day.

Right: the width of inhibition rings.

7. Agar diffusion test of AgNCs40 and AgNCs100 embedded zein films on E. coli cells. 

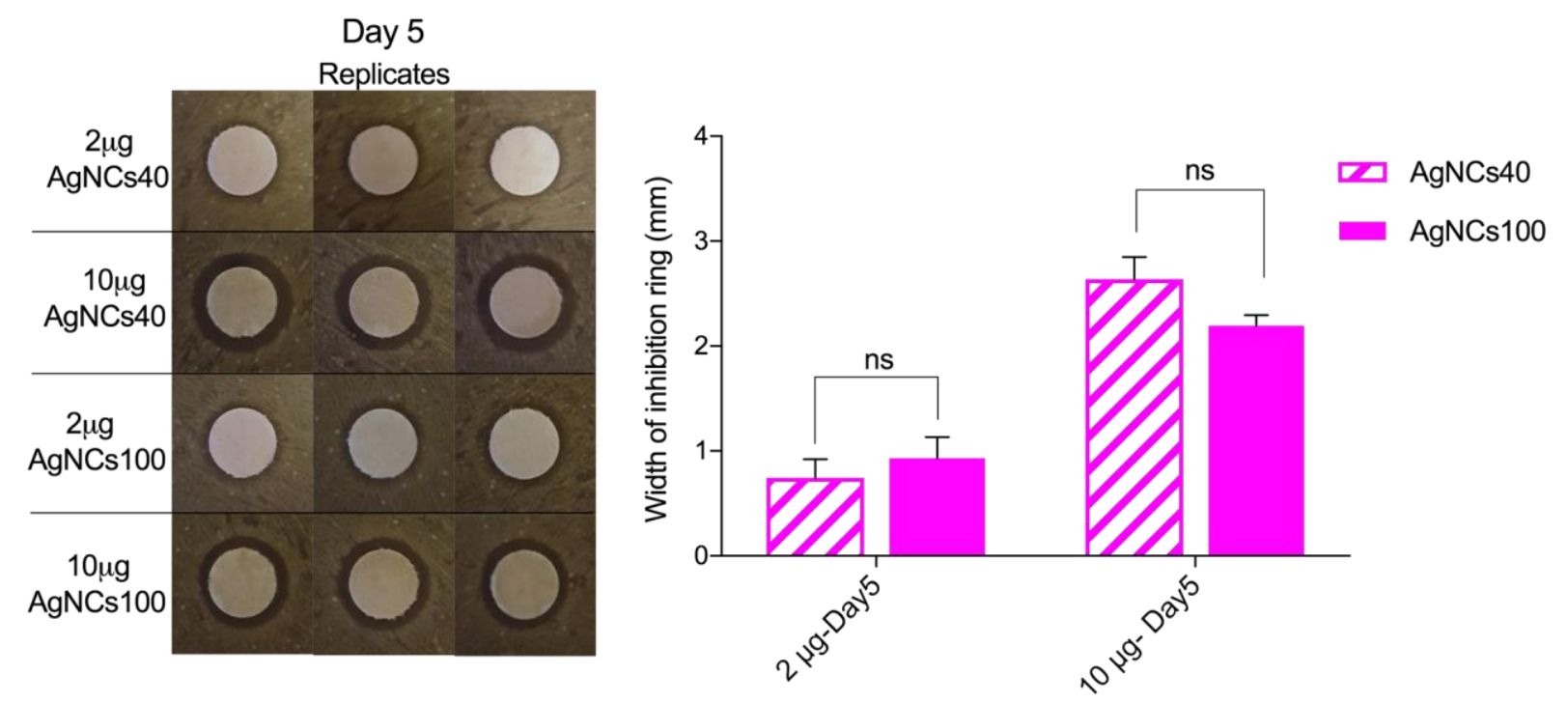

Figure S6. Inhibition ring of zein film embedding silver nanolcusters synthesized by 40 minutes (AgNCs40) and 100 minutes (AgNCs100) UVA radiation. Left: Inhibition zone of E. coli treated by $2 \mu \mathrm{g}$ and $10 \mu \mathrm{g}$ AgNCs 40 and AgNCs 100 for 5 days. Right: the width of inhibition rings $($ ns $>0.9999, n=3)$. 